\title{
Protocol for management of odontogenic keratocysts considering recurrence according to treatment methods
}

\author{
Fadi Titinchi \\ Department of Maxillo-Facial and Oral Surgery, Faculty of Dentistry and WHO Collaborating Centres, \\ University of the Western Cape, Cape Town, South Africa
}

\begin{abstract}
J Korean Assoc Oral Maxillofac Surg 2020;46:358-360)
The management of odontogenic keratocysts (OKC) remains a hotly debated topic in oral and maxillofacial surgery. Despite numerous studies and systematic reviews on treatment options, there is a lack of consensus and no accepted protocol on the management of OKC. Hence, the aim of this study was to briefly summarize all large systematic reviews in the literature on the management of OKC and formulate an evidence-based management protocol. Data from five large systematic reviews were combined to calculate the mean recurrence rate for each technique. Decompression followed by enucleation along with adjuvant methods such as application of Carnoy's solution and peripheral ostectomy can result in very low recurrence and is an acceptable first line treatment. The surgical approach should be determined by lesion size, patient age, proximity to vital structures, accessibility, soft tissue/cortical perforation, and if the lesion is recurrent.
\end{abstract}

Key words: Odontogenic cyst, Keratocysts, Treatment, Recurrence, Clinical protocols

[paper submitted 2020. 5. 28 / revised 1st 2020. 7. 5, 2nd 2020. 8. 1, 3rd 2020. 8. 4 / accepted 2020. 8. 10]

Numerous surgical methods have been practiced in the management of odontogenic keratocysts (OKC); however, much confusion still exists as to which methods provide the lowest recurrence rates (RR) without causing significant morbidity. These methods are divided into conservative and aggressive/radical approaches or a combination of the two. Conservative methods include simple enucleation and marsupialization/decompression ${ }^{1}$. Adjuvant methods such as peripheral ostectomy, cryotherapy (liquid nitrogen) and Carnoy's solution are considered aggressive forms of treatment which have shown more promising outcomes ${ }^{1}$. Radical methods involve mainly resection which yields the lowest RR however causes significant morbidity ${ }^{1}$.

\footnotetext{
Fadi Titinchi

Department of Maxillo-Facial and Oral Surgery, Faculty of Dentistry and WHO Collaborating Centres, University of the Western Cape, Private Bag X1, Tygerberg Oral Health Center, Francie Van Zijl Drive, Cape Town 7505, South Africa

TEL: +27-21-937-3086 FAX: +27-21-931-2287

E-mail: ftitinchi@uwc.ac.za

ORCID: https://orcid.org/0000-0003-3182-7038

(c) This is an open-access article distributed under the terms of the Creative Commons Attribution Non-Commercial License (http://creativecommons.org/ licenses/by-nc/4.0/), which permits unrestricted non-commercial use, distribution, and reproduction in any medium, provided the original work is properly cited. Copyright (C) 2020 The Korean Association of Oral and Maxillofacial Surgeons. All rights reserved.
}

It is currently considered that enucleation alone is an inadequate form of treatment and needs to be used in combination with adjuvant methods to lower $\mathrm{RR}^{2,3}$. Epithelial remnants and satellite/daughter cysts can easily be left behind after enucleation which leads to high RR $(20.8 \%-26.1 \%)^{4}$.

Decompression is a modified marsupialization technique which causes the cyst to decrease significantly in size and the cystic lining becomes thicker resembling oral mucosa that allows for easier enucleation ${ }^{2}$. This method decreases the levels of IL-1 $\alpha$ which regulates epithelial cell proliferation in $\mathrm{OKC}$; hence, there is immune-histochemical evidence that decompression is superior to enucleation alone ${ }^{2}$. de Castro et $\mathrm{al}^{4}$ reported RR of OKC treated by decompression followed by enucleation $(11.9 \%)$ to be significantly lower than enucleation alone (20.8\%).

Peripheral ostectomy is an aggressive form of adjuvant therapy where methylene blue is utilized to stain any cystic remnants and a rosehead bur is used to remove these ${ }^{2}$. Cryotherapy with liquid nitrogen causes cell necrosis of the cystic lining as with chemical curettage with Carnoy's solution ${ }^{2}$. All these methods reduce RR when compared to enucleation or marsupialization/decompression alone; however, these methods can cause damage to adjacent structures ${ }^{2}$. Resection provides the least recurrences (RR, $0 \%-8.4 \%)^{5,6}$. 
Data from five large systematic reviews reporting on RR for different treatment modalities were combined (Table 1) and these formed the basis for developing a management protocol for $\mathrm{OKCs}^{1,4-7}$.(Fig. 1) The protocol highlights the role of advanced imaging in $\mathrm{OKC}$ management. Magnetic resonance imaging (MRI) is the only non-invasive modality that characterizes OKC accurately, preoperatively. T2-weighted images show hyper-intensity with signal drop out which is highly suggestive of OKC $(85 \% \text { sensitivity })^{8}$. Computed tomography $(\mathrm{CT})$ can detect cortical perforations ${ }^{8}$.

Table 1. Summary of recurrence rates for different surgical methods in the management of odontogenic keratocysts

\begin{tabular}{|c|c|c|c|c|c|c|c|}
\hline Study & $\begin{array}{l}\text { Enucleation } \\
\text { alone }\end{array}$ & $\begin{array}{l}\text { Enucleation \& } \\
\text { peri ostectomy }\end{array}$ & $\begin{array}{l}\text { Enucleation } \\
\text { \& Carnoy's } \\
\text { solution }\end{array}$ & $\begin{array}{c}\text { Enucleation \& } \\
\text { cryotherapy }\end{array}$ & $\begin{array}{c}\text { Marsupialization/ } \\
\text { decompression } \\
\text { alone }\end{array}$ & $\begin{array}{c}\text { Decompression } \\
\text { \& residual } \\
\text { cystectomy }\end{array}$ & Resection \\
\hline Al-Moraissi et al. ${ }^{1}$ (2017) & 23.10 & 17.40 & 11.50 & 14.50 & 32.30 & 14.60 & 8.40 \\
\hline de Castro et al. ${ }^{4}$ (2018) & 20.80 & NA & NA & NA & 18.50 & 11.90 & NA \\
\hline $\begin{array}{l}\text { Chrcanovic and Gomez }{ }^{7} \\
\text { (2017) }\end{array}$ & 22.50 & 18.60 & 5.30 & 20.90 & 28.70 & 18.60 & 2.20 \\
\hline Johnson et al. ${ }^{5}(2013)$ & 25.60 & NA & 7.90 & 30.30 & NA & 15.80 & 6.30 \\
\hline Kaczmarzyk et al. $^{6}$ (2012) & 26.09 & 18.18 & 50 & NA & 40 & NA & 0 \\
\hline Total & 23.60 & 18.10 & 18.70 & 21.90 & 29.90 & 15.20 & 4.20 \\
\hline
\end{tabular}

(NA: not available)

Values are presented as \%.

Fadi Titinchi: Protocol for management of odontogenic keratocysts considering recurrence according to treatment methods. J Korean Assoc Oral Maxillofac Surg 2020

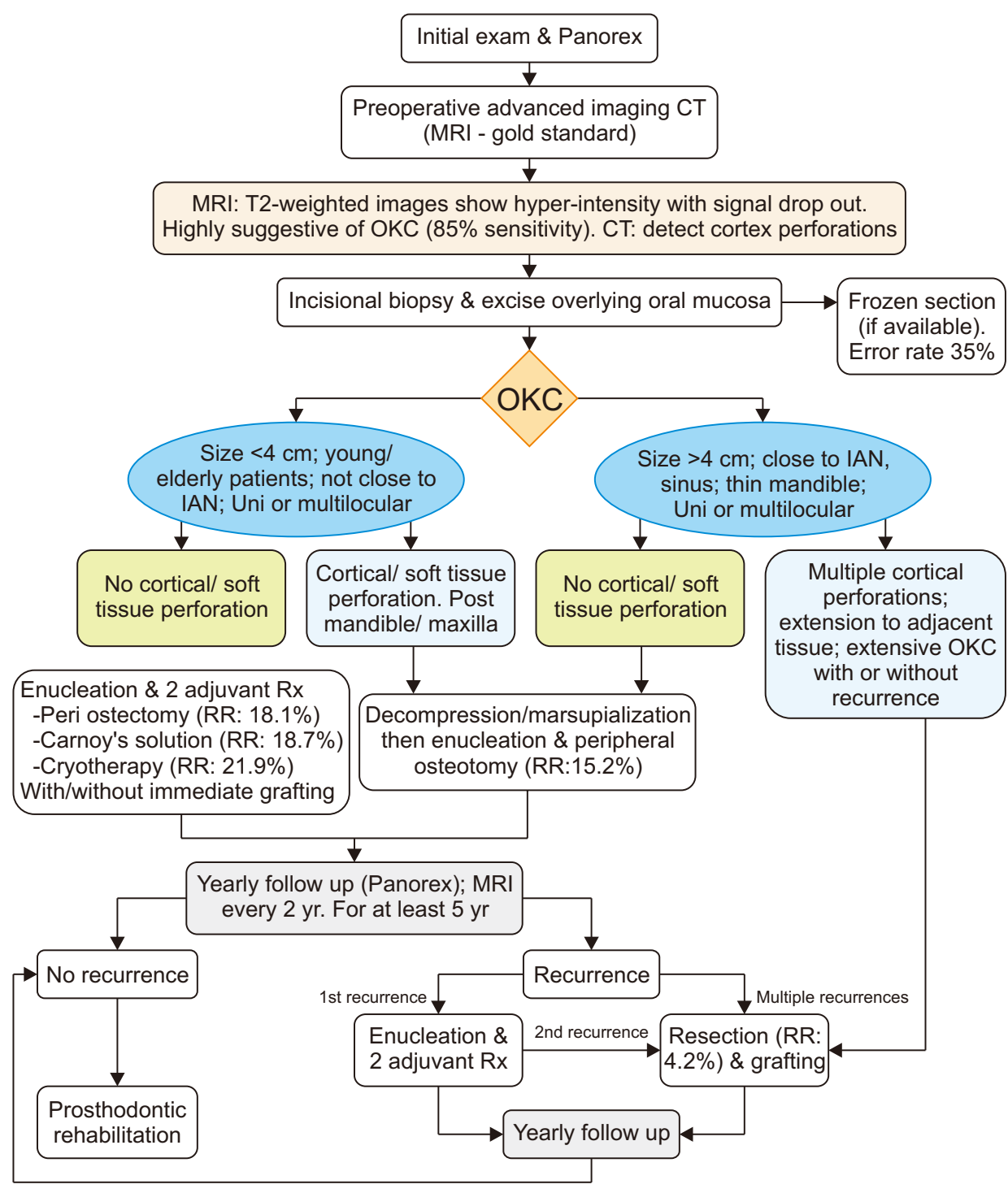

Fig. 1. Management protocol for odontogenic keratocysts (OKC). (CT: computed tomography, MRI: magnetic resonance imaging, IAN: inferior alveolar nerve, $\mathrm{Rx}$ : treatment, RR: recurrence rates)

Fadi Titinchi: Protocol for management of odontogenic keratocysts considering recurrence according to treatment methods. J Korean Assoc Oral Maxillofac Surg 2020 
Other important factors in lowering the RR of OKC include excision of the overlying oral mucosa, especially at the time of biopsy, as studies have shown that approximately all recurrent $\mathrm{OKCs}$ contain epithelial islands and micro-cysts in the mucosa overlying areas of cortical perforation ${ }^{9}$.

The surgical approach is determined by size, patient age, proximity to vital structures, accessibility, soft tissue/cortical perforation, and if the lesion is recurrent. Age is an important factor in the recurrence of $\mathrm{OKC}$, with younger patients (especially those in their second to third decade of life) experiencing higher RR that should be managed more aggressively ${ }^{10}$. Decompression followed by enucleation has been shown to reduce RR (15.2\%). If this technique is followed by an adjuvant method such as application of Carnoy's solution and peripheral ostectomy, it can result in very low recurrence and is an acceptable first line of treatment ${ }^{6}$. If the lesion is accessible and not large in size, then enucleation of the cyst should be performed along with 2 adjuvant methods. Resection should be reserved for multiple recurrent lesions, multiple cortical perforations, and soft tissue extension.

OKC should be monitored closely with yearly panoramic radiographs ${ }^{2}$. MRI should be performed every 2 years to detect early recurrences ${ }^{8}$. Follow-up should be for at least 10 years $^{2}$. Bone grafting and rehabilitation can be performed early in cases of resection, a thin mandibular cortex, and large lesions that were treated with cryotherapy ${ }^{2}$. Bone grafting should be delayed in recurrent lesions ${ }^{2}$.

In conclusion, an evidence-based protocol for management of OKCs has been proposed. In order to reduce recurrence and morbidity, a systematic approach should be implemented based on presenting factors and sound evidence-based treatment options. This protocol can also be used as a valuable educational tool for patients.

\section{Author's Contributions}

F.T. designed the study and performed data analysis and wrote the manuscript.

\section{Conflict of Interest}

No potential conflict of interest relevant to this article was reported.

\section{References}

1. Al-Moraissi EA, Dahan AA, Alwadeai MS, Oginni FO, Al-Jamali $\mathrm{JM}$, Alkhutari AS, et al. What surgical treatment has the lowest recurrence rate following the management of keratocystic odontogenic tumor?: a large systematic review and meta-analysis. J Craniomaxillofac Surg 2017;45:131-44. https://doi.org/10.1016/ j.jcms.2016.10.013

2. Pogrel MA. The keratocystic odontogenic tumor. Oral Maxillofac Surg Clin North Am 2013;25:21-30, v. https://doi.org/10.1016/ j.coms.2012.11.003

3. Tomomatsu N, Uzawa N, Michi Y, Kurohara K, Okada N, Amagasa T. Clinical study of keratocystic odontogenic tumors. J Korean Assoc Oral Maxillofac Surg 2012;38:55-63. https://doi. org/10.5125/jkaoms.2012.38.1.55

4. de Castro MS, Caixeta CA, de Carli ML, Ribeiro Júnior NV, Miyazawa M, Pereira AAC, et al. Conservative surgical treatments for nonsyndromic odontogenic keratocysts: a systematic review and meta-analysis. Clin Oral Investig 2018;22:2089-101. https://doi. org $/ 10.1007 / \mathrm{s} 00784-017-2315-8$

5. Johnson NR, Batstone MD, Savage NW. Management and recurrence of keratocystic odontogenic tumor: a systematic review. Oral Surg Oral Med Oral Pathol Oral Radiol 2013;116:e271-6. https:// doi.org/10.1016/j.oooo.2011.12.028

6. Kaczmarzyk T, Mojsa I, Stypulkowska J. A systematic review of the recurrence rate for keratocystic odontogenic tumour in relation to treatment modalities. Int J Oral Maxillofac Surg 2012;41:75667. https://doi.org/10.1016/j.ijom.2012.02.008

7. Chrcanovic BR, Gomez RS. Recurrence probability for keratocystic odontogenic tumors: an analysis of 6427 cases. J Craniomaxillofac Surg 2017;45:244-51. https://doi.org/10.1016/ j.jcms.2016.11.010

8. van Rensburg LJ, Paquette M, Morkel JA, Nortjé CJ. Correlative MRI and CT imaging of the odontogenic keratocyst: a review of twenty-one cases. Oral Maxillofac Surg Clin North Am 2003;15:363-82. https://doi.org/10.1016/S1042-3699(03)00037-2

9. Al-Moraissi EA, Pogrel MA, Ellis E 3rd. Does the excision of overlying oral mucosa reduce the recurrence rate in the treatment of the keratocystic odontogenic tumor? A systematic review and meta-analysis. J Oral Maxillofac Surg 2016;74:1974-82. https:// doi.org/10.1016/j.joms.2016.03.043

10. Titinchi F, Nortje CJ. Keratocystic odontogenic tumor: a recurrence analysis of clinical and radiographic parameters. Oral Surg Oral Med Oral Pathol Oral Radiol 2012;114:136-42. https://doi. org/10.1016/j.oooo.2012.01.032

How to cite this article: Titinchi F. Protocol for management of odontogenic keratocysts considering recurrence according to treatment methods. J Korean Assoc Oral Maxillofac Surg 2020;46:358360. https://doi.org/10.5125/jkaoms.2020.46.5.358 